\title{
The Number of Medical Imaging Services in Latvia and Lithuania
}

\author{
Alida Vane \\ Turiba University, \\ Riga, Latvia \\ vanealida@gmail.com
}

\author{
Iveta Linina \\ Turiba University, \\ Riga, Latvia \\ Iveta.Linina@turiba.lv
}

\author{
Helena Skadina \\ Turiba University, \\ Riga, Latvia \\ helena.skadina@gmail.com
}

\begin{abstract}
The increase in medical imaging services has a significant impact on healthcare costs. The study analyses the dynamics of a number of medical imaging services in Latvia, Lithuania, and in England for comparison (20122016), which shows that the number of medical imaging examinations increases in all the countries covered by the study. Moreover, there are significant differences in the application of those services in Latvia and Lithuania if compared to England, which may indicate to inefficient resource management and differences (or absence) of diagnostic guidelines. The following research methods have been used for the research: monographic or descriptive method and graphical method for visualisation, and analysis of visual information.
\end{abstract}

Keywords-examinations, health, radiations.

\section{INTRODUCTION}

In recent years, the high and ever-growing costs of healthcare systems due to technological innovation and an ageing population are a significant and pressing issue in almost all economies [1], [2]. Diagnostics is an integral part of healthcare and provides a more accurate diagnosis of the type, cause, and severity of a disease. Diagnosis allows for a more precise treatment plan [3]. The advances in medical technology in both diagnostics and treatment have contributed to a rapid increase in healthcare spending [4]. Expanding medical imaging services has a significant impact on healthcare costs, healthcare quality, and healthcare risks. As the number of

radiological examinations increases, the risk of radioactive exposure increases as well, which is not always beneficial to patient care [5]. One of the strategic objectives of the World Health Organisation (WHO) is to ensure the availability, quality, and correct use of medical devices (instruments). In May 2007, the WHO Assembly expressed concerns about the inadequate investment in healthcare technologies related to medical devices (instruments) that do not meet national priorities and are used irrationally or misused, thus wasting money [6]. The WHO states that the increase in the availability of medical devices would increase the number of imaging procedures significantly [7]. Efficient use of resources (medical imaging instruments in this case) is discussed not only in terms of a number of examinations performed with one device but also in terms of a number of completed examinations per population in comparative economies (Latvia, Lithuania). The authors of the study assume that the higher performance corresponds with the worse efficiency because it increases the overall cost of healthcare. The study uses data from public databases (such as NHS England, OECD), as well as the data received on demand from Latvia and Lithuania.

The study was aimed at showing the differences between the number of medical imaging services in Latvia and Lithuania and the number of examinations performed with them compared to England that can indicate the efficiency of the instrument use. To achieve the overall goal, the following tasks were set:

1. Compare the number of medical imaging devices and the number of examinations in the OECD countries.

2. Compare the number of examinations performed with medical imaging devices in Latvia and Lithuania in comparison to England.

The study is based on the data from the Organisation for Economic Co-operation and Development (OECD) between 2012 and 2016 (or last published) [8]. In OECD statistics, data is available on a number of Computed Tomography, Positron Emission Tomography (PET), Magnetic Resonance, whereas the data on most commonly used devices such as X-ray and ultrasound instruments have not been aggregated. The authors obtained data from Latvia (Center for Disease Prevention and Control), Lithuania (Hygiene Institute), and England [9]. There is a decentralised healthcare system in the United Kingdom, so only national data for England were used in the research. The following research methods have been used for the study: monographic or descriptive method and graphical method for visualisation, and analysis of visual information.

\section{RESULTS AND DISCUSSION}

Modern medical imaging has direct benefits, which include more efficient surgical treatment, shorter stay in the hospital, elimination of diagnostic surgery, better cancer diagnosis and treatment, more efficient post-trauma treatment, better stroke treatment, better heart disease treatment, and rapid diagnostics of life-threatening vascular conditions such as mesenteric ischemia [10]. These benefits require new imaging instruments and expand their use in diagnostic and treatment. Over the past decade, 
imaging services and their costs have risen about twice as much as other healthcare technologies [10]. The most significant number of Computed Tomography (CT) devices per million population (Table 1) is in Australia (62.95), while the smallest number is detected in Mexico (6.12). Hence, the number of imaging devices differs tenfold in OECD countries. In five countries (Luxembourg, Lithuania, Austria, Iceland, and the United States of America), the number of CT instruments has decreased. In its turn, an increase of $117 \%$ was observed in Chile reaching 24.27 units per million population; an increase of $25 \%$ was noticed in France reaching 16.92 units per million population, an increase of $25 \%$ in Australia leading to 62.95 units per million population.

TABLE 1 Computed tomography unit per million population [8]

\begin{tabular}{|c|c|c|c|}
\hline Country & \begin{tabular}{llll} 
& \multicolumn{1}{l}{} & $\mathrm{h}$ & $\mathrm{e}$ \\
2 & 0 & 1 & 2 \\
year & &
\end{tabular} & $\begin{array}{l}\text { The } 2016 \\
\text { year or } \\
\text { last avail- } \\
\text { able }\end{array}$ & 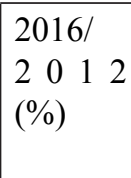 \\
\hline Mexico & 5.11 & 6.12 & $120 \%$ \\
\hline Hungary & 7.66 & 8.86 & $116 \%$ \\
\hline United Kingdom & 9.09 & 9.46 & $104 \%$ \\
\hline Israel & 9.1 & 9.71 & $107 \%$ \\
\hline Netherlands & 10.92 & 13.04 & $119 \%$ \\
\hline Slovenia & 12.64 & 14.04 & $111 \%$ \\
\hline Turkey & 13.53 & 14.53 & $107 \%$ \\
\hline Canada & 14.68 & 15.28 & $104 \%$ \\
\hline Czech Republic & 15.03 & 15.52 & $103 \%$ \\
\hline France & 13.49 & 16.92 & $125 \%$ \\
\hline Luxembourg & 24.48 & 17.14 & $70 \%$ \\
\hline Ireland & 16.74 & 17.24 & $103 \%$ \\
\hline Slovak Republic & 15.53 & 17.31 & $111 \%$ \\
\hline Poland & 15.4 & 17.33 & $113 \%$ \\
\hline Estonia & 17.39 & 17.48 & $101 \%$ \\
\hline New Zealand & 15.43 & 17.9 & $116 \%$ \\
\hline Spain & 17.19 & 18.26 & $106 \%$ \\
\hline Lithuania & 23.76 & 23.01 & $97 \%$ \\
\hline Finland & 21.8 & 24.2 & $111 \%$ \\
\hline Chile & 11.18 & 24.27 & $217 \%$ \\
\hline Austria & 29.77 & 29.07 & $98 \%$ \\
\hline Italy & 33.29 & 34.29 & $103 \%$ \\
\hline Germany & 34.01 & 35.17 & $103 \%$ \\
\hline Latvia & 32.44 & 36.23 & $112 \%$ \\
\hline Greece & 33.41 & 36.66 & $110 \%$ \\
\hline Korea & 36.93 & 37.8 & $102 \%$ \\
\hline Iceland & 40.53 & 38.76 & $96 \%$ \\
\hline Switzerland & 34.64 & 38.93 & $112 \%$ \\
\hline Denmark & 33.09 & 39.11 & $118 \%$ \\
\hline United States & 43.87 & 41.82 & $95 \%$ \\
\hline Australia & 50.48 & 62.95 & $125 \%$ \\
\hline
\end{tabular}

The largest number of Magnetic Resonance (MR) devices per million population (Table 2) is found in the United States of America (36.69), while the smallest number is found in Mexico (2.57). The number of MR devices differs 14 times in OECD countries. Only in two countries, the number of MR devices is declining, that is, Luxembourg and Iceland. The most substantial increase in the number of MR instruments was stated in Australia (160\%), Chile (114\%), France (56\%), Poland, and the Slovak Republic (43\%).

TABLE 2

Magnetic resonance units per million population [8].

\begin{tabular}{|l|l|l|l|}
\hline Country & $\begin{array}{c}\text { The } \\
2012 \\
\text { year }\end{array}$ & $\begin{array}{c}\text { The 2016 } \\
\text { year or last } \\
\text { available }\end{array}$ & $\begin{array}{c}2016 / 2012 \\
(\%)\end{array}$ \\
\hline Mexico & 2.16 & 2.57 & $119 \%$ \\
\hline Hungary & 2.82 & 3.97 & $141 \%$ \\
\hline Israel & 3.29 & 4.91 & $149 \%$ \\
\hline United Kingdom & 7.16 & 7.23 & $101 \%$ \\
\hline Poland & 5.49 & 7.87 & $143 \%$ \\
\hline Czech Republic & 6.95 & 8.52 & $123 \%$ \\
\hline Slovak Republic & 6.29 & 9.02 & $143 \%$ \\
\hline Chile & 4.41 & 9.43 & $214 \%$ \\
\hline Canada & 8.86 & 9.49 & $107 \%$ \\
\hline Turkey & 9.58 & 10.55 & $110 \%$ \\
\hline Slovenia & 8.75 & 11.14 & $127 \%$ \\
\hline Luxembourg & 13.18 & 12 & $91 \%$ \\
\hline Lithuania & 10.04 & 12.2 & $122 \%$ \\
\hline Netherlands & 11.82 & 12.8 & $108 \%$ \\
\hline France & 8.65 & 13.52 & $156 \%$ \\
\hline Estonia & 9.83 & 13.68 & $139 \%$ \\
\hline Latvia & 9.83 & 13.78 & $140 \%$ \\
\hline New Zealand & 11.12 & 13.85 & $125 \%$ \\
\hline Australia & 5.5 & 14.29 & $260 \%$ \\
\hline Ireland & 12.39 & 14.72 & $119 \%$ \\
\hline Spain & 14.77 & 15.92 & $108 \%$ \\
\hline Iceland & 21.83 & 20.87 & $96 \%$ \\
\hline Austria & 19.1 & 22.43 & $117 \%$ \\
\hline Finland & 21.61 & 25.48 & $118 \%$ \\
\hline Greece & 21.91 & 26.63 & $122 \%$ \\
\hline Korea & 34.44 & 36.69 & $119 \%$ \\
\hline Italy & 27.81 & $115 \%$ \\
\hline Germany & 34.49 & $120 \%$ \\
\hline United States & $107 \%$ \\
\hline & 28.62 & \\
\hline
\end{tabular}

When comparing the loading of medical imaging devices in Latvia (data Center for Disease Prevention and Control Latvia) and Lithuania (data Hygiene Institute Lithuania) in 2016 (Table 3), we can see that X-rays instruments are used 1.66 times more efficiently in Latvia than in Lithuania, CT instruments are used 1.14 times more efficiently, while MR devices are used 1.07 times more efficiently in Lithuania than in Latvia. USG 
equipment is applied equally in both countries.

TABLE 3

Number of examinations per medical imaging unit in 2016

\begin{tabular}{|l|l|l|c|}
\hline Equipment & Latvia & Lithuania & $\begin{array}{c}\text { highest value/ } \\
\text { lowest value }\end{array}$ \\
\hline X-rays & 10.375 & 6.235 & 1.66 \\
\hline CT & 4.923 & 4.337 & 1.14 \\
\hline MR & 3.460 & 3.692 & 1.07 \\
\hline USG & 1.766 & 1.759 & 1.00 \\
\hline
\end{tabular}

The number of medical imaging devices cannot be the only comparator. One does not know the age of medical devices, whether end-of-life equipment is written off when new imaging devices are bought, which are safer for patients (reduced radiation time, reduced examination time [11]), or the use of those devices continues. It is quite important because the latest generation imaging instruments are more advanced and have better image quality, as well as less exposure for a human. Is equipping with medical technology based on a number of examinations and are the devices loaded maximally? In all three countries compared (Fig. 1, 2, 3), the total number of medical imaging services is growing, as well as the number of methods considered separately, id est., Magnetic Resonance (MR), Computed Tomography (CT), radiography (X-rays), and ultrasonography (USG), is increasing.

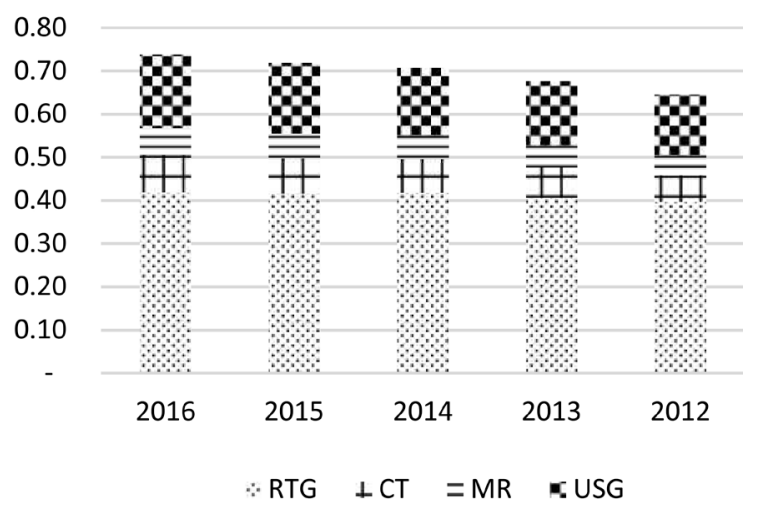

Fig. 1. The number of examinations per capita in England (2012-2016 year) [9]

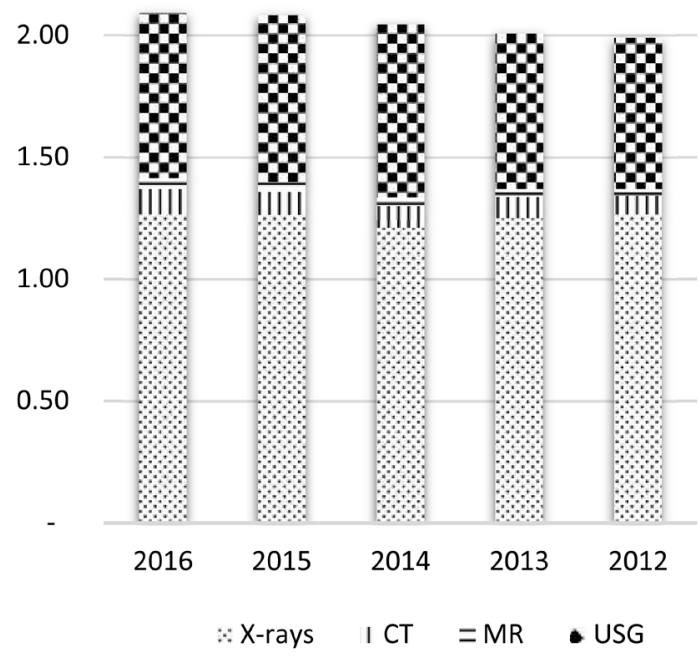

Fig. 2. The number of examinations per capita in Lithuania (20122016 year), (data Hygiene Institute Lithuania)

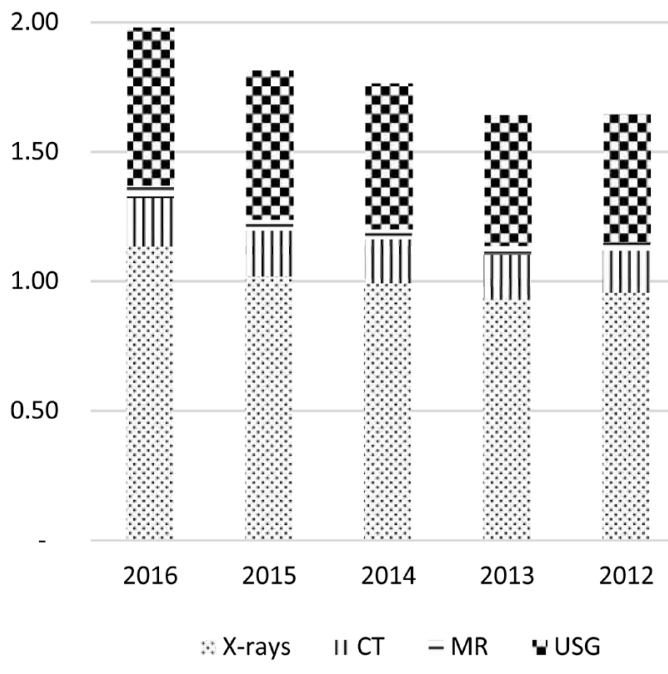

Fig. 3. The number of examinations per capita in Latvia (2012-2016 year), (data Center for Disease Prevention and Control Latvia)

The total number of examinations is the largest, namely, 2.09, in Lithuania; the total number of examinations is 1.98 in Latvia and 0.74 in England per capita per year, Which is almost 3 times less than in Lithuania. Figure 4 illustrates the vast difference between England and Latvia, Lithuania in each type of medical imaging examination in 2016.

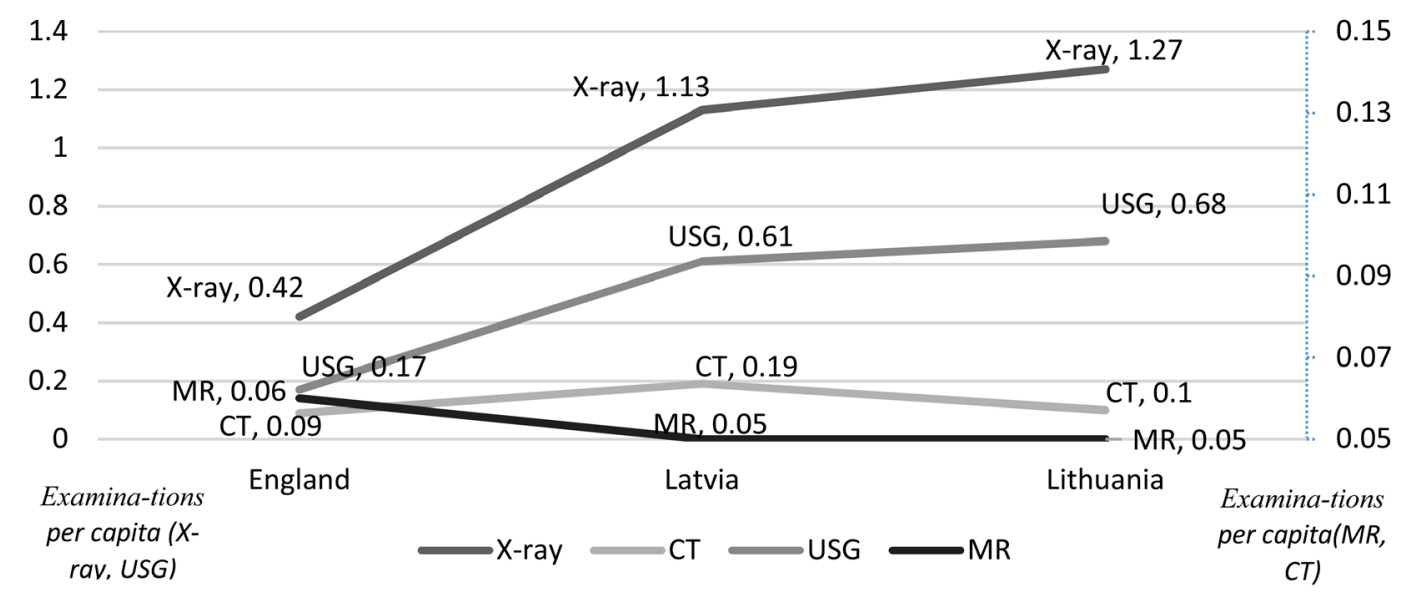

Fig. 4. The number of examinations per capita in 2016 year 
The increase in the number of examinations per capita over the five years (2012-2016) is observed in all the countries studied (Table 4-6). The fastest percentage growth is MR examinations in Latvia ( $+68 \%$ ), Lithuania $(+63 \%)$, and England $(+40 \%)$, while the growth rate of CT examinations is the fastest in England $(+40 \%)$, Lithuania (+29\%), and Latvia (+15\%). The number of X-ray examinations per capita in Latvia (+19\%), England $(+6 \%)$, Lithuania $(+0.4 \%)$ as well as USG examinations are also increasing.

TABLE 4

Number of examinations per capita Latvia

\begin{tabular}{|c|c|c|c|c|c|c|}
\hline & 2016. & 2015.y & 2014.y & 2013.y & 2012.y & $\begin{array}{c}2016 . \mathrm{y} / \\
2012 . \mathrm{y}(\%)\end{array}$ \\
\hline X-rays & 1.13 & 1.02 & 0.99 & 0.93 & 0.95 & $119 \%$ \\
\hline CT & 0.19 & 0.18 & 0.17 & 0.17 & 0.16 & $115 \%$ \\
\hline MR & 0.05 & 0.04 & 0.04 & 0.03 & 0.03 & $168 \%$ \\
\hline USG & 0.61 & 0.58 & 0.56 & 0.51 & 0.50 & $123 \%$ \\
\hline
\end{tabular}

TABLE 5

Number of examinations per capita Lithuania

\begin{tabular}{|c|c|c|c|c|c|c|}
\hline & $2016 . \mathrm{y}$ & $2015 . \mathrm{y}$ & $2014 . \mathrm{y}$ & $2013 . \mathrm{y}$ & $2012 . \mathrm{y}$ & $\begin{array}{c}2016 . \mathrm{y} / \\
2012 . \mathrm{y}(\%)\end{array}$ \\
\hline X-rays & 1.27 & 1.26 & 1.21 & 1.25 & 1.26 & $100.4 \%$ \\
\hline CT & 0.10 & 0.09 & 0.09 & 0.09 & 0.08 & $129 \%$ \\
\hline MR & 0.05 & 0.04 & 0.04 & 0.03 & 0.03 & $163 \%$ \\
\hline USG & 0.68 & 0.68 & 0.71 & 0.64 & 0.62 & $109 \%$ \\
\hline
\end{tabular}

TABLE 6

Number of examinations per capita England

\begin{tabular}{|c|c|c|c|c|c|c|}
\hline & 2016. y & 2015.y & 2014. y & 2013.y & 2012.y & $\begin{array}{c}\text { 2016.y/ } \\
\text { 2012.y (\% ) }\end{array}$ \\
\hline X-rays & 0.42 & 0.42 & 0.42 & 0.41 & 0.40 & $106 \%$ \\
\hline CT & 0.09 & 0.08 & 0.08 & 0.07 & 0.06 & $140 \%$ \\
\hline MR & 0.06 & 0.06 & 0.05 & 0.05 & 0.04 & $140 \%$ \\
\hline USG & 0.17 & 0.16 & 0.16 & 0.15 & 0.14 & $119 \%$ \\
\hline
\end{tabular}

\section{CONCLUSIONS}

In most countries, the number of medical imaging devices is growing significantly, but there is a huge difference in access to common healthcare services among the OECD countries. A large number of examinations does not always indicate that the population has access to these examinations, as shown by the example of Latvia, where are long queues for state-funded imaging services. For instance, an individual must wait between 50 and 180 days for an MR examination in Latvia [12]. To identify the productivity of imaging instruments precisely, one should study a number of examinations performed by each individual imaging device, as specific productivity will depend on a number of population at a particular location, where the device is installed. In a sparsely neighboured area, the productivity of imaging device can be lower than in a densely populated area. There are significant differences in the number of medical imaging services in Latvia and Lithuania if compared to England, so additional research is needed to compare this indicator in as many countries as possible so that correct conclusions can be drawn on the reasons why the differences in the number of examinations are so significant. The authors consider that the lack of precise medical guidelines in Latvia and Lithuania is the primary reason resulting in unjustified examinations being performed and medical imaging services being overused. The study [10] identifies the ways to tackle causes to reduce the overuse of imaging devices. The authors agree that the countries with a high number of medical examinations (such as Latvia and Lithuania) should develop evidence-based eligibility criteria, draft comprehensive guidelines, educate attending physicians, patients, and the public because patients demand imaging examinations (they have read about them or have seen advertising). It is also essential to introduce a payment reform for imaging services so that no payment is made for individual examinations, thus creating economic incentives. Providing maximum control over double examinations is crucial by ensuring a single database of all the examinations. All the countries are recommended to publish open data as well as to grant access to medical data for further scientific advancement to improve the efficiency of national medical services. 


\section{REFERENCES}

[1] T. Czypionka; M. Kraus; S. Mayer; G. Röhrling "Efficiency, ownership, and financing of hospitals: The case of Austria", 2014 Dec; Vol. 17 (4), pp. 331-47; Publisher: Baltzer Science Publishers; Database: MEDLINE. https://doi.org/10.1007/s10729-013-9256-9

[2] D. Shinjo and T. Aramaki, "Geographic distribution of healthcare resources, healthcare service provision, and patient flow in Japan: A cross-sectional study", Social Science \& Medicine, December 2012, https://doi.org/10.1016/j.socscimed.2012.07.032

[3] Deloitte Centre for Health Solutions, "Working differently to provide early diagnosis. Improving access to diagnostics", 2013, https://www2.deloitte.com/uk/en/pages/life-sciences-and-healthcare/articles/working-differently-to-provide-early-diagnosis.html

4] Weisbrod, A. Burton; "The Health Care Quadrilemma: An Essay on Technological Change, Insurance, Quality of Care, and Cost Containment." Journal of Economic Literature 29, No 2 (1991): 523-52. http://www.jstor.org/stable/2727522.

[5] G. Holt, D. Rahota, I. Unita, "Aspects regarding the radiological examinations in the Bihor county between 2008-2012", Romanian Journal of Functional \& Clinical, Macro- \& Microscopical Anatomy \& of Anthropology / Revista Româna de Anatomie Functionala si Clinica, Macro si Microscopica si de Antropologie. 2013, Vol. 12 Issue 2, p. 185-189. 5p., http://revanatomie.ro/en/abstract.php?an $\underline{\mathrm{rev}}=2013 \mathrm{\& nr}$ rev $=2 \& \mathrm{kn} \_$art $=21$
[6] WHO, Sixtieth World Health Assembly Geneva, 14-23 May 2007 Resolutions and Decisions Annexes, pp. 106, http://apps.who.int/ $\mathrm{gb} / \mathrm{ebwha/pdf}$ files/whassa_wha60-rec1/e/whass1_wha60rec1-en. pdf

[7] WHO, https://www.who.int/diagnostic imaging/en/

[8] OECD Data extracted on 02 Feb 2019 14:01 UTC (GMT) from OECD. Stat https://stats.oecd.org/

[9] NHS England https://www.england.nhs.uk/statistics/wp-content/ uploads/sites/2/2017/11/Annual-Statistical-Release-2016-17-DIDPDF-1.5MB.pdf

[10] W.R.Hendee, G.J.Becker, Eds., "Original Research Free Access Special Reports Addressing Overutilization in Medical Imaging", 2010, https://pubs.rsna.org/doi/full/10.1148/radiol.10100063, https://doi.org/10.1148/radiol.10100063

[11] H.Hricak, D.J.Brenner, Eds., "Managing Radiation Use in Medical Imaging: A Multifaceted Challenge", 2011, https://pubs.rsna. org/doi/full/10.1148/radiol.10101157, https://doi.org/10.1148/radiol.10101157

[12] http://rindapiearsta.lv/lv/mekle_isako , 11.02.201 